\title{
Intravenous versus oral etoposide: efficacy and correlation to clinical outcome in patients with high-grade metastatic gastroenteropancreatic neuroendocrine neoplasms (WHO G3)
}

\author{
Abir Salwa Ali ${ }^{1}$. Malin Grönberg ${ }^{1} \cdot$ Seppo W. Langer ${ }^{2,3} \cdot$ Morten Ladekarl $^{4}$. Geir Olav Hjortland ${ }^{5}$. \\ Lene Weber Vestermark ${ }^{6}$. Pia Österlund ${ }^{7,8}$. Staffan Welin ${ }^{1} \cdot$ Henning Grønbæk $^{9}$. Ulrich Knigge ${ }^{2,3}$. \\ Halfdan Sorbye $^{10} \cdot$ Eva Tiensuu Janson $^{1}$
}

Received: 25 January 2018 / Accepted: 23 February 2018 / Published online: 6 March 2018

(c) The Author(s) 2018. This article is an open access publication

\begin{abstract}
High-grade gastroenteropancreatic neuroendocrine neoplasms (GEP-NENs, G3) are aggressive cancers of the digestive system with poor prognosis and survival. Platinum-based chemotherapy (cisplatin/carboplatin + etoposide) is considered the first-line palliative treatment. Etoposide is frequently administered intravenously; however, oral etoposide may be used as an alternative. Concerns for oral etoposide include decreased bioavailability, inter- and intra-patient variability and patient compliance. We aimed to evaluate possible differences in progression-free survival (PFS) and overall survival (OS) in patients treated with oral etoposide compared to etoposide given as infusion. Patients $(n=236)$ from the Nordic NEC study were divided into three groups receiving etoposide as a long infusion ( $24 \mathrm{~h}, n=170)$, short infusion ( $\leq 5 \mathrm{~h}, n=33)$ or oral etoposide ( $n=33$ ) according to hospital tradition. PFS and OS were analyzed with Kaplan-Meier (log-rank), cox proportional hazard ratios and confidence intervals. No statistical differences were observed in PFS or OS when comparing patients receiving long infusion (median PFS 3.8 months, median OS 14.5 months), short infusion (PFS 5.6 months, OS 11.0 months) or oral etoposide (PFS 5.4 months, OS 11.3 months). We observed equal efficacy for the three administration routes suggesting oral etoposide may be safe and efficient in treating high-grade GEP-NEN, G3 patients scheduled for cisplatin/carboplatin + etoposide therapy.
\end{abstract}

Keywords Chemotherapy $\cdot$ Intravenous $\cdot$ Oral $\cdot$ Etoposide $\cdot$ Neuroendocrine neoplasms $\cdot$ WHO G3

Abir Salwa Ali

abir.ali@medsci.uu.se

1 Department of Medical Sciences, Section of Endocrine Oncology, Uppsala University, Uppsala, Sweden

2 Departments of Surgery C and Endocrinology PE, Rigshospitalet, Faculty of Health Science, University of Copenhagen, Copenhagen, Denmark

3 Department of Oncology, Copenhagen University Hospital Rigshospitalet, Copenhagen, Denmark

4 Department of Oncology, Aarhus University Hospital, Aarhus, Denmark

5 Department of Oncology, Oslo University Hospital, Oslo, Norway
6 Department of Oncology, Odense University Hospital, Odense, Denmark

7 Department of Oncology, Tampere University Hospital and Tampere University, Tampere, Finland

8 Department of Oncology, Helsinki University Hospital and Helsinki University, Helsinki, Finland

9 Departments of Hepatology and Gastroenterology, Aarhus University Hospital, Aarhus, Denmark

10 Department of Oncology, Haukeland University Hospital, Bergen, Norway 


\section{Introduction}

Gastroenteropancreatic neuroendocrine neoplasms (GEPNENs) with proliferation index $(\mathrm{Ki} 67)>20 \%$ and/or mitoses $>20$ per $2 \mathrm{~mm}^{2}$ are aggressive tumors that belong to the Grade 3 (G3) group in the WHO classification of tumors of the digestive system with an expected 5-year survival of $16 \%$ [1-3]. The majority of these tumors are characterized as poorly differentiated and called neuroendocrine carcinomas (NECs) although a subgroup of welldifferentiated G3 tumors has been recognized recently [4]. In the most recent WHO classification, pancreatic well-differentiated NENs G3 are denoted pancreatic NET-G3 [5].

GEP-NENs G3, excluding pulmonary NENs, account for approximately $50 \%$ of all NENs G3 with primary tumors in esophagus, stomach, pancreas, colon and rectum. However, they present with cancer of unknown primary (CUP) in 30\% of the cases [6]. An increase in incidence has been observed during the last years. However, treatment efficacy does not seem to improve at the same rate $[3,7]$. In the Nordic NEC study of 305 patients, median overall survival (OS) was 11 months for patients treated with chemotherapy and 1 month for untreated patients. Pancreatic tumors showed a median OS of 15 months, while rectal and colon tumors had median OS of 10.0 and 8 months, respectively, indicating that OS differs with primary tumor location $[6,8]$. Other reported factors indicating a better prognosis are Ki67 index $<55 \%$, normal serum lactate dehydrogenase (LDH) and platelet count as well as good performance status [6].

Platinum-based combination chemotherapy with cisplatin/carboplatin and etoposide is the first-line treatment for GEP-NENs $[9,10]$. This treatment regimen has been agreed upon and is used by the Nordic, European and North American Societies of neuroendocrine tumors [11-13]. Clinical practices on route of administration of etoposide for these GEP-NEN patients differ and are mainly due to hospital specific recommendations.

Chemotherapy has for years been given through an intravenous (IV) route of administration for a variety of cancers although there has been a rise in oral anticancer drugs [14]. There is a general perception that anticancer drugs are best given intravenously but this has been challenged by the development of new formulations of drugs with increased stability and bioavailability. The growing number of alternatives in oral formulations is giving rise to a shift in attitudes and practices but still concerns remain $[14,15]$.

IV administration of etoposide holds several advantages. The ability of etoposide to exert its topoisomerase inhibitory effect is directly correlated to the concentration and duration of etoposide in the blood [16]. IV formulations allow for a higher bioavailability of a drug in the blood stream and therefore have been seen as the preferred route of administration but this also comes with disadvantages such as long hospital stays and elevated costs for hospitals as well as impact on patients' quality of life. Another disadvantage with IV administration is the use of solvents that are toxic upon repeated administration [15-17].

Oral etoposide is an alternative still being debated. Concerns of using oral etoposide include the decreased bioavailability, inter- and intra-patient variability as well as for the risk of decreased patient compliance [14, 17]. Most studies show a bioavailability of etoposide ranging between 30 and $76 \%$ with a nonlinear absorption that decreases in bioavailability with increased dosage.

In this study, we examined the differences in treatment efficacy measured as progression-free survival (PFS) and OS for patients receiving etoposide as short or long infusions ( $\leq 5$ or $24 \mathrm{~h}$ ) compared to oral etoposide (O.E.).

\section{Materials and methods}

\section{Patient and tumor characteristics}

This study cohort included patients diagnosed with a GEP-NEN G3 with a primary tumor located in esophagus, stomach, pancreas, colon, rectum and a subgroup of CUPs (Table 1). CUP was defined as a NEN G3 diagnosed in a patient with predominant abdominal metastases but where no primary tumor could be identified.

Patients were collected from the Nordic NEC study, resulting in 236 patients, diagnosed 1995-2012, in whom the route of etoposide administration could be verified. Clinical data were obtained from the Nordic NEC register [6]. The cohort included patients that received platinum-based combination chemotherapy (cisplatin/carboplatin + etoposide); cisplatin was given as an infusion to all 236 patients. Patients were given etoposide as short infusion $(\leq 5 \mathrm{~h})$, long infusion (24 h), or oral tablet (O.E.). The choice of route of etoposide administration was based on hospital preferences, and thus, all patients at a certain hospital were treated in the same way.

All tumors were immunoreactive (IR) for synaptophysin and/or chromogranin A ( $\mathrm{CgA})$ and all tumors had Ki67 index $\geq 20 \%$ counted in hot spot areas.

\section{Statistical analyses}

Efficacy of etoposide in the three groups was assessed with regard to PFS and OS. The defined event was death from tumor progression. PFS was defined as the time from the first treatment until time of the first progression and OS was 
Table 1 Patient and baseline disease characteristics

\begin{tabular}{|c|c|c|c|}
\hline & $\begin{array}{l}\text { IV } 24 \mathrm{~h}, n(\%) \\
170\end{array}$ & $\begin{array}{l}\mathrm{IV} \leq 5 \mathrm{~h}, n(\%) \\
33\end{array}$ & $\begin{array}{l}\text { O.E., } n(\%) \\
33\end{array}$ \\
\hline \multicolumn{4}{|l|}{$\operatorname{Sex}$} \\
\hline Male & $86(51)$ & $20(61)$ & $18(55)$ \\
\hline Female & $84(49)$ & $13(39)$ & $15(45)$ \\
\hline \multicolumn{4}{|l|}{ Primary tumor } \\
\hline Esophagus & $6(3)$ & $2(6)$ & $0(0)$ \\
\hline Stomach & $10(6)$ & $2(6)$ & $4(12)$ \\
\hline Pancreas & $48(28)$ & $8(24)$ & $10(31)$ \\
\hline Colon & $35(21)$ & $7(21)$ & $4(12)$ \\
\hline Rectum & $12(7)$ & $3(9)$ & $3(9)$ \\
\hline CUP & $59(35)$ & $11(34)$ & $12(36)$ \\
\hline \multicolumn{4}{|c|}{ Chromogranin A immunoreactivity } \\
\hline Positive & $142(86)$ & $24(80)$ & $26(85)$ \\
\hline Negative & $23(14)$ & $6(20)$ & $4(15)$ \\
\hline \multicolumn{4}{|c|}{ Synaptophysin immunoreactivity } \\
\hline Positive & $153(94)$ & $33(100)$ & $29(94)$ \\
\hline Negative & $9(6)$ & $0(0)$ & $2(6)$ \\
\hline \multicolumn{4}{|l|}{ Performance status } \\
\hline 0 & $59(37)$ & $11(34)$ & $8(25)$ \\
\hline 1 & $83(52)$ & $16(48)$ & $17(53)$ \\
\hline 2 & $14(9)$ & $5(15)$ & $6(19)$ \\
\hline 3 & $3(2)$ & $1(3)$ & $1(3)$ \\
\hline \multicolumn{4}{|l|}{$L D H$} \\
\hline Normal & $55(41)$ & $11(33)$ & $18(62)$ \\
\hline Elevated & $80(59)$ & $22(67)$ & $11(38)$ \\
\hline \multicolumn{4}{|l|}{ Metastatic stage } \\
\hline Local & $7(4)$ & $3(9)$ & $1(3)$ \\
\hline Regional & $41(24)$ & $4(12)$ & $6(18)$ \\
\hline Distant & $122(72)$ & $26(79)$ & $26(79)$ \\
\hline \multicolumn{4}{|l|}{ Ki67 } \\
\hline$<55 \%$ & $79(46)$ & $19(58)$ & $17(52)$ \\
\hline$\geq 55 \%$ & $91(54)$ & $14(42)$ & $16(48)$ \\
\hline \multicolumn{4}{|l|}{ Response } \\
\hline Complete & $5(3)$ & $0(0)$ & $2(7)$ \\
\hline Partial & $41(26)$ & $8(29)$ & $8(27)$ \\
\hline Stable disease & $59(37)$ & $10(35,5)$ & $13(43)$ \\
\hline Progressed disease & $54(34)$ & $10(35.5)$ & $7(23)$ \\
\hline
\end{tabular}

Performance status: ECOG the Eastern Cooperative Oncology Group consensus for performance status, Response RECIST criteria, IV intravenous, $L D H$ lactate dehydrogenase, O.E. oral etoposide

defined as the time from diagnosis of NEN G3 until date of death from neuroendocrine cancer; or if event was not found, censored at date of last observation.

Kaplan-Meier plots were used for PFS and OS analysis, and the log-rank test was used to compare curve separation according to type of etoposide administration. Cox proportional regression was performed for the estimation of hazard ratios (HRs) and confidence intervals (CIs). The two groups receiving IV infusions were compared to patients receiving O.E. Using a multivariate regression model, variables hypothesized to correlate with the clinical outcome were included to ensure that they would not confound with the analysis. These analyses were performed on dichotomized variables: sex (male vs. female), $\mathrm{CgA}$ (positive vs. negative), performance status ECOG $(0+1$ vs. $2+3)$, LDH (normal vs. elevated) and $\mathrm{Ki} 67$ (<55 vs. $\geq 55 \%$ ). All statistical analyses were performed using IBM SPSS statistics software (v25, USA).

\section{Ethics}

The study was approved and the need for consent was waived by the local ethics committee, Regionala etikprövningsnämnden (EPN), in Uppsala, Sweden (ref: 2008/397).

\section{Results}

\section{Baseline patient characteristics}

Of the 236 patients included, 170 (72\%) were given long infusions, oral etoposide and short infusions were given to 33 patients, respectively (Table 1). The median age in the whole cohort group was 61 years (range 27-85 years). Ki67 index was $>55 \%$ in $54 \%$ of all the patients. All included patients died due to their malignant disease. The distribution of variables such as sex, performance status, $\mathrm{CgA}$ immunohistochemical expression, LDH levels, metastatic disease and treatment response was similar in all three groups. Adverse events were not recorded in the Nordic NEC registry, and hence, analysis of the safety profile could not be performed. Patient and disease characteristics are presented in Table 1.

\section{Survival data}

PFS and OS showed no differences between the three groups. Median PFS for the whole cohort was 4.6 months and OS 13 months (Fig. 1a, b). Median PFS for the IV $24 \mathrm{~h}$ was 3.8 months, 5.6 months for $5 \mathrm{~h}$ infusion and 5.4 months for oral treatment. OS was also similar between the three groups; 14.5 months for IV $24 \mathrm{~h}, 11$ months for 5-h infusion and 11.3 for oral administration.

\section{Association between administration and prognosis}

Kaplan-Meier analysis for the three administrations did not show differences in PFS and OS (Fig. 1c, $p=0.67$, Fig. 1d, $p=0.59$ ). Additional analyses, comparing survival curves for 3 and 6 months, showed no differences in the short-term progression between the three groups (data not shown). 

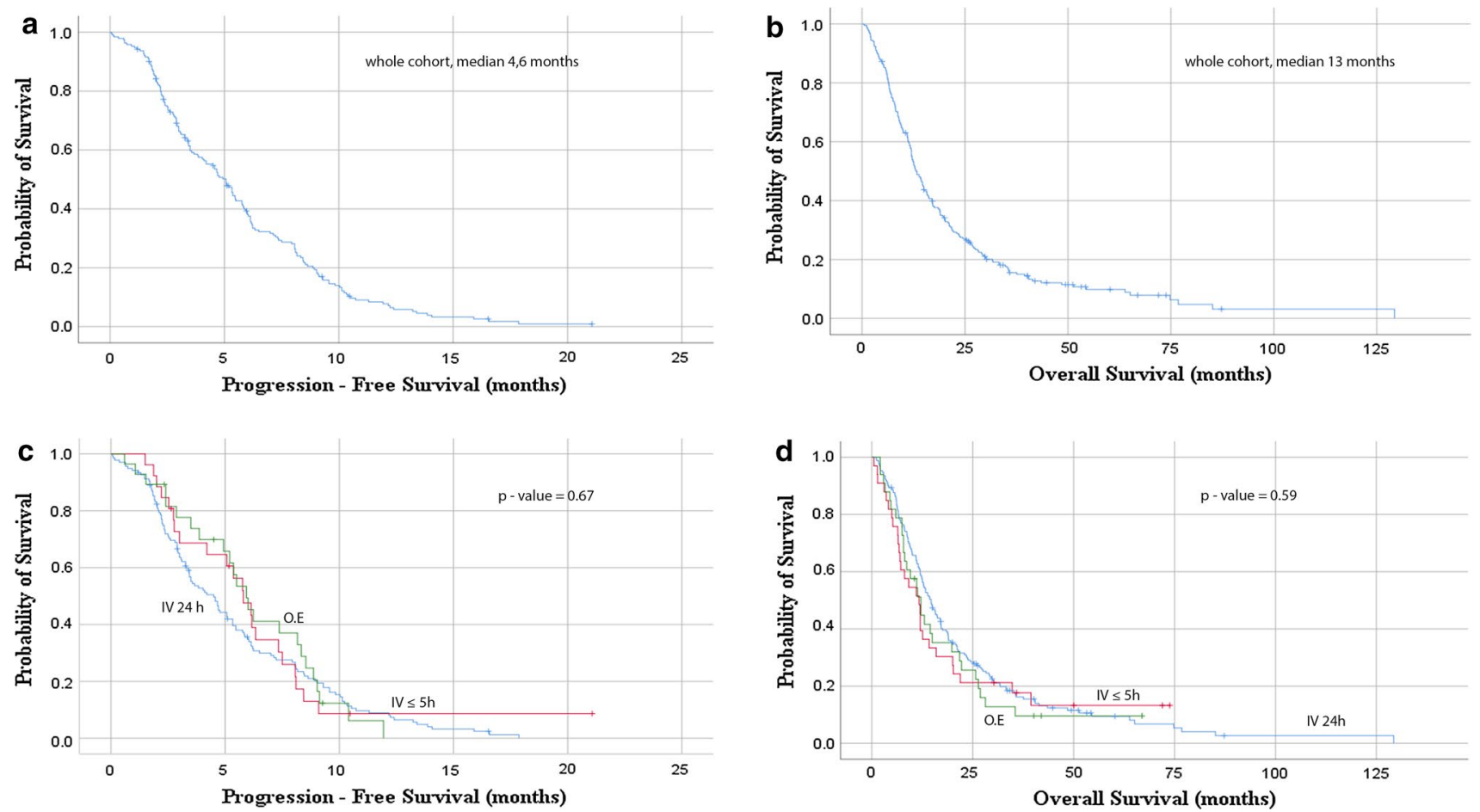

Fig. 1 Kaplan-Meier curves for PFS and OS. a PFS for whole cohort; b OS for whole cohort; c, d PFS and OS for the three administrations, intravenous long infusion (IV $24 \mathrm{~h}$ ), intravenous short infusion (IV $<5 \mathrm{~h}$ ) and oral etoposide (O.E.)

To assess the effect of administration on survival, cox regression models for univariate and multivariate analyses were used. We found no differences in progression and OS on the basis of administration when comparing oral administration to short and long infusion (Table 2, $p=0.54$ and $p=0.91$ for PFS and $p=0.38$ and $p=0.90$ for OS). A worse performance status and elevated LDH were significantly associated with poorer survival. Patients with performance status $2+3$ showed an almost doubled risk of progression $(p=0.01)$ compared with patients with performance status 0 and 1 and almost four times poorer survival $(p<0.01)$. Elevated LDH levels also associated significantly to shorter time to progression and poorer survival in this patient cohort. Patients with elevated LDH level had a 50\% higher risk of progression and $70 \%$ risk of dying ( $p=0.01$ and $p<0.01$, respectively). Data are summarized in Table 2.

In the multivariate model adjusted for sex, $\mathrm{Ki} 67, \mathrm{CgA}$, performance status, LDH and metastatic stage, no statistical associations between administration route and progression/ survival were found (Table 3).

\section{Discussion}

In this large Nordic NEC register-based study, we examined differences in disease progression and survival for patients receiving etoposide as $24 \mathrm{~h}$ infusions, shorter infusions or O.E. The main finding is that there was no statistically significant differences between the three administration groups, which suggest that no one of these administration routes is superior to another.

The cox regression analyses showed that none of the administration groups in particular were associated to better or poorer PFS or OS. Additional analyses to further exclude the risk of confounding factors showed no significant differences between the three groups.

The data from this study suggest that, although more frequently used, IV formulations may not be the ultimate route of administration.

Studies of head-to-head comparisons between IV etoposide and O.E. are limited with conflicting data. Some studies suggest that O.E. is better or at least equally effective as IV etoposide and some studies report the opposite. O.E. given to patients with ovarian cancer and prostate cancer as the second-line treatment showed the same or better efficacy and safety as IV administration [18, 19]. In a study on patients with castration-resistant prostate cancer, the efficacy, compliance and safety profile did not differ between etoposide given IV versus orally [19]. These results suggest, in accordance with our results, that O.E. may be a valuable option to consider when treating patients with etoposide.

A study on patients with non-small cell lung cancer demonstrated that the safety profile for O.E. is significantly better to that of IV etoposide. In this cohort, there was a 
Table 2 Univariate analysis

\begin{tabular}{|c|c|c|c|c|}
\hline & \multicolumn{2}{|c|}{$\begin{array}{l}\text { Progression-free } \\
\text { survival }\end{array}$} & \multicolumn{2}{|c|}{ Overall survival } \\
\hline & HR $(95 \%$ CI $)$ & $p$ value & $\operatorname{HR}(95 \% \mathrm{CI})$ & $p$ value \\
\hline \multicolumn{5}{|l|}{ Administration } \\
\hline $\begin{array}{l}\mathrm{IV} \leq 5 \mathrm{~h} \text { versus } \\
\text { O.E. }\end{array}$ & $1.2(0.7-1.8)$ & 0.54 & $0.8(0.6-1.2)$ & 0.38 \\
\hline $\begin{array}{l}\text { IV } 24 \mathrm{~h} \text { versus } \\
\text { O.E. }\end{array}$ & $1.0(0.5-1.7)$ & 0.91 & $1.0(0.6-1.6)$ & 0.90 \\
\hline \multicolumn{5}{|l|}{$\operatorname{Sex}$} \\
\hline $\begin{array}{l}\text { Male versus } \\
\text { female }\end{array}$ & $1.0(0.7-1.3)$ & 0.92 & $0.9(0.7-1.2)$ & 0.65 \\
\hline \multicolumn{5}{|l|}{ Ki67 } \\
\hline$<55$ versus $\geq 55 \%$ & $1.0(0.7-1.3)$ & 0.92 & $1.3(0.9-1.7)$ & 0.12 \\
\hline \multicolumn{5}{|c|}{ CgA immunoreactivity } \\
\hline $\begin{array}{l}\text { Positive versus } \\
\text { negative }\end{array}$ & $1.0(0.7-1.5)$ & 0.92 & $1.3(0.9-1.9)$ & 0.23 \\
\hline \multicolumn{5}{|c|}{ ECOG performance status } \\
\hline $0+1$ versus $2+3$ & $1.8(1.2-2.8)$ & $0.01 * *$ & $3.8(2.5-5.7)$ & $<0.01 * *$ \\
\hline \multicolumn{5}{|l|}{$L D H$} \\
\hline $\begin{array}{l}\text { Normal versus } \\
\text { elevated }\end{array}$ & $1.5(1.1-2.1)$ & $0.01 * *$ & $1.7(1.3-2.4)$ & $<0.01 * *$ \\
\hline \multicolumn{5}{|l|}{ Metastatic stage } \\
\hline $\begin{array}{l}\text { Local versus } \\
\text { distant }\end{array}$ & $1.0(0.4-2.6)$ & 0.96 & $0.9(0.5-1.8)$ & 0.76 \\
\hline $\begin{array}{l}\text { Regional versus } \\
\text { distant }\end{array}$ & $0.9(0.4-2.4)$ & 0.95 & $1.0(0.5-2.0)$ & 0.91 \\
\hline
\end{tabular}

Hazard ratio (HR) and 95\% confidence intervals (CI) obtained from cox regression models

$C g A$ chromogranin A, ECOG the Eastern Cooperative Oncology Group consensus for performance status, $I V$ intravenous, $L D H$ lactate dehydrogenase, O.E. oral etoposide

*Correlation is significant at the 0.05 level

**Correlation is significant at the 0.01 level

significantly higher need for hospitalization due to neutropenia in the IV group compared to the oral group [20].

However, results favoring IV formulations have also been demonstrated. There are limitations of oral chemotherapy that may be the cause of their slow implementation in the clinic, such as variability in concentrations, uptake and safety profile. A study showed that O.E. has three times higher intra-patient variability and twice as high inter-patient variability when compared to IV formulation of the drug [17]. How important these inter- and intra-patient variabilities are for the survival of the patients is not concluded. Drug-drug interaction is another concern when giving etoposide orally. Etoposide interacts with the commonly used antifungal agent, ketoconazole, resulting in an increase in the etoposide concentration systemically [21].

The oral administration route for etoposide is an easier, by patients often preferred approach rather than IV infusions. An 89\% preference for oral chemotherapy compared to IV
Table 3 Multivariate analysis

\begin{tabular}{|c|c|c|c|c|}
\hline & \multicolumn{2}{|c|}{$\begin{array}{l}\text { Progression-free } \\
\text { survival }\end{array}$} & \multicolumn{2}{|c|}{ Overall survival } \\
\hline & HR $(95 \%$ CI $)$ & $p$ value & HR $(95 \%$ CI $)$ & $p$ value \\
\hline \multicolumn{5}{|l|}{ Administration } \\
\hline $\begin{array}{l}\text { IV } \leq 5 \text { h versus } \\
\text { O.E. }\end{array}$ & $1.2(0.7-2.2)$ & 0.42 & $1.1(0.6-1.8)$ & 0.79 \\
\hline $\begin{array}{l}\text { IV } 24 \mathrm{~h} \text { versus } \\
\text { O.E. }\end{array}$ & $1.0(0.5-1.9)$ & 0.99 & $1.1(0.6-1.9)$ & 0.86 \\
\hline \multicolumn{5}{|l|}{ Sex } \\
\hline $\begin{array}{l}\text { Male versus } \\
\text { female }\end{array}$ & $0.9(0.7-1.3)$ & 0.71 & $0.8(0.6-1.1)$ & 0.22 \\
\hline \multicolumn{5}{|l|}{ Ki67 } \\
\hline $\begin{array}{l}<55 \text { versus } \\
\geq 55 \%\end{array}$ & $1.1(0.8-1.6)$ & 0.57 & $1.3(0.9-1.8)$ & 0.17 \\
\hline \multicolumn{5}{|c|}{ CgA immunoreactivity } \\
\hline $\begin{array}{l}\text { Positive versus } \\
\text { negative }\end{array}$ & $0.7(0.4-1.1)$ & 0.13 & $0.8(0.5-1.3)$ & 0.35 \\
\hline \multicolumn{5}{|c|}{ ECOG performance status } \\
\hline $0+1$ versus $2+3$ & $1.9(1.2-3.3)$ & $<0.01 * *$ & $3.8(2.4-6.2)$ & $<0.01 * *$ \\
\hline \multicolumn{5}{|l|}{$L D H$} \\
\hline $\begin{array}{l}\text { Normal versus } \\
\text { elevated }\end{array}$ & $1.4(0.7-2.0)$ & 0.07 & $1.6(1.1-2.2)$ & $0.02 *$ \\
\hline \multicolumn{5}{|l|}{ Metastatic stage } \\
\hline $\begin{array}{l}\text { Local versus } \\
\text { distant }\end{array}$ & $1.1(0.4-2.9)$ & 0.88 & $1.2(0.6-2.6)$ & 0.62 \\
\hline $\begin{array}{l}\text { Regional versus } \\
\text { distant }\end{array}$ & $0.9(0.4-2.5)$ & 0.91 & $1.2(0.6-2.5)$ & 0.59 \\
\hline
\end{tabular}

Hazard ratio (HR) and 95\% confidence intervals (CI) obtained from cox regression models

$C g A$ chromogranin A, ECOG the Eastern Cooperative Oncology Group consensus for performance status, $I V$ intravenous, $L D H$ lactate dehydrogenase, O.E. oral etoposide

*Correlation is significant at the 0.05 level

**Correlation is significant at the 0.01 level

was reported in a study from 1997 and in a meta-analysis of 13 research papers in 2016, the reported preference for oral chemotherapy was $85 \%$. These results indicate a strong patient preference for oral administration, with no clear studies refuting the use of oral chemotherapy [22, 23]. Oral chemotherapy also decreases the cost associated with hospital stays for infusions, and it decreases the pains of puncture wounds in patients and offers a more convenient alternative. The cost effectiveness of oral chemotherapy has been investigated in few studies and many times with favorable outcome for the oral formulations [24, 25].

In conclusion, there are no conclusive results to indicate which route of administration of etoposide is superior. Our results indicate that the three ways of administrating etoposide did not differ with regard to efficacy in PFS or OS and that oral may be favorable option for cancer patients in a palliative setting. 
Previously, studies have shown conflicting results leading to a disadvantage for oral chemotherapy being used clinically. However, our data imply that oral administration of etoposide may be a good alternative for GEP-NEN G3 patients. Prospective studies are needed in order to validate and establish a consensus on the efficacy of oral chemotherapy and whether this option is being overlooked with regard to cost effectiveness, safety and patient preference.

Funding This study was funded by the Swedish Cancer Society (CAN558/2014), the Lions Foundation for Cancer Research at the Uppsala University Hospital and Selander foundation and the foundation for International Studies at the Faculty of Health Science, University of Copenhagen.

\section{Compliance with ethical standards}

Conflict of interest The authors declare that they have no conflict of interest.

Open Access This article is distributed under the terms of the Creative Commons Attribution 4.0 International License (http://creativeco mmons.org/licenses/by/4.0/), which permits unrestricted use, distribution, and reproduction in any medium, provided you give appropriate credit to the original author(s) and the source, provide a link to the Creative Commons license, and indicate if changes were made.

\section{References}

1. Bosman FT, World Health Organization, International Agency for Research on Cancer. WHO classification of tumours of the digestive system. World Health Organization classification of tumours. 4th ed. Lyon: IARC Press; 2010.

2. Basturk O, Yang Z, Tang LH, Hruban RH, Adsay V, McCall $\mathrm{CM}$, et al. The high-grade (WHO G3) pancreatic neuroendocrine tumor category is morphologically and biologically heterogenous and includes both well differentiated and poorly differentiated neoplasms. Am J Surg Pathol. 2015;39(5):683-90. https://doi.org/10.1097/PAS.0000000000000408.

3. Sorbye H, Strosberg J, Baudin E, Klimstra DS, Yao JC. Gastroenteropancreatic high-grade neuroendocrine carcinoma. Cancer. 2014;120(18):2814-23. https://doi.org/10.1002/cncr.28721.

4. Tang LH, Basturk O, Sue JJ, Klimstra DS. A practical approach to the classification of WHO grade 3 (G3) well-differentiated neuroendocrine tumor (WD-NET) and poorly differentiated neuroendocrine carcinoma (PD-NEC) of the pancreas. Am J Surg Pathol. 2016;40(9):1192-202. https://doi.org/10.1097/ PAS.0000000000000662.

5. Klöppel GK, David S, Hruban RH, Adsay V, Capella C, Couvelard A, Komminoth P, La Rosa S, Ohike N, Osamura RY, Perren A, Scoazec J-Y, Rindi G. Pancreatic neuroendocrine tumors: update on the new world health organization classification. AJSP Rev Rep. 2017;22(5):233-9.

6. Sorbye H, Welin S, Langer SW, Vestermark LW, Holt N, Osterlund $\mathrm{P}$, et al. Predictive and prognostic factors for treatment and survival in 305 patients with advanced gastrointestinal neuroendocrine carcinoma (WHO G3): the NORDIC NEC study. Ann Oncol. 2013;24(1):152-60. https://doi.org/10.1093/annon c/mds 276
7. Ilett EE, Langer SW, Olsen IH, Federspiel B, Kjaer A, Knigge U. Neuroendocrine carcinomas of the gastroenteropancreatic system: a comprehensive review. Diagnostics (Basel). 2015;5(2):119-76. https://doi.org/10.3390/diagnostics5020119.

8. Haugvik SP, Janson ET, Osterlund P, Langer SW, Falk RS, Labori KJ, et al. Surgical treatment as a principle for patients with high-grade pancreatic neuroendocrine carcinoma: a nordic multicenter comparative study. Ann Surg Oncol. 2016;23(5):1721-8. https://doi.org/10.1245/s1043 4-015-5013-2.

9. Bongiovanni A, Riva N, Ricci M, Liverani C, La Manna F, De Vita A, et al. First-line chemotherapy in patients with metastatic gastroenteropancreatic neuroendocrine carcinoma. OncoTargets Ther. 2015;8:3613-9. https://doi.org/10.2147/OTT.S91971.

10. Moertel CG, Kvols LK, O'Connell MJ, Rubin J. Treatment of neuroendocrine carcinomas with combined etoposide and cisplatin. Evidence of major therapeutic activity in the anaplastic variants of these neoplasms. Cancer. 1991;68(2):227-32.

11. Strosberg JR, Coppola D, Klimstra DS, Phan AT, Kulke MH, Wiseman GA, et al. The NANETS consensus guidelines for the diagnosis and management of poorly differentiated (highgrade) extrapulmonary neuroendocrine carcinomas. Pancreas. 2010;39(6):799-800. https://doi.org/10.1097/MPA.0b013e3181 ebb56f.

12. Janson ET, Sorbye H, Welin S, Federspiel B, Gronbaek H, Hellman P, et al. Nordic guidelines 2014 for diagnosis and treatment of gastroenteropancreatic neuroendocrine neoplasms. Acta Oncol. 2014;53(10):1284-97. https://doi.org/10.3109/02841 86X.2014.941999.

13. Garcia-Carbonero R, Sorbye H, Baudin E, Raymond E, Wiedenmann B, Niederle B, et al. ENETS consensus guidelines for high-grade gastroenteropancreatic neuroendocrine tumors and neuroendocrine carcinomas. Neuroendocrinology. 2016;103(2):186-94. https://doi.org/10.1159/000443172.

14. O'Neill VJ, Twelves CJ. Oral cancer treatment: developments in chemotherapy and beyond. Br J Cancer. 2002;87(9):933-7. https://doi.org/10.1038/sj.bjc.6600591.

15. Rezonja R, Knez L, Cufer T, Mrhar A. Oral treatment with etoposide in small cell lung cancer-dilemmas and solutions. Radiol Oncol. 2013;47(1):1-13. https://doi.org/10.2478/ raon-2013-0008.

16. Chabot GG, Armand JP, Terret C, de Forni M, Abigerges D, Winograd B, et al. Etoposide bioavailability after oral administration of the prodrug etoposide phosphate in cancer patients during a phase I study. J Clin Oncol. 1996;14(7):2020-30. https ://doi.org/10.1200/JCO.1996.14.7.2020.

17. Hande K, Messenger M, Wagner J, Krozely M, Kaul S. Inter- and intrapatient variability in etoposide kinetics with oral and intravenous drug administration. Clin Cancer Res. 1999;5(10):2742-7.

18. van der Burg ME, de Wit R, van Putten WL, Logmans A, Kruit WH, Stoter G, et al. Weekly cisplatin and daily oral etoposide is highly effective in platinum pretreated ovarian cancer. $\mathrm{Br} \mathbf{J}$ Cancer. 2002;86(1):19-25. https://doi.org/10.1038/sj.bjc.66000 02.

19. Caubet M, Dobi E, Pozet A, Almotlak H, Montcuquet P, Maurina $\mathrm{T}$, et al. Carboplatin-etoposide combination chemotherapy in metastatic castration-resistant prostate cancer: a retrospective study. Mol Clin Oncol. 2015;3(6):1208-12. https://doi. org/10.3892/mco.2015.628.

20. Jeremic B, Shibamoto Y, Milicic B, Milisavljevic S, Nikolic $\mathrm{N}$, Dagovic A, et al. Prolonged oral versus high-dose intravenous etoposide in combination with carboplatin for stage IV non-small-cell lung cancer (NSCLC): a randomized trial. Lung Cancer. 1999;25(3):207-14. 
21. Yong WP, Desai AA, Innocenti F, Ramirez J, Shepard D, Kobayashi K, et al. Pharmacokinetic modulation of oral etoposide by ketoconazole in patients with advanced cancer. Cancer Chemother Pharmacol. 2007;60(6):811-9. https://doi. org/10.1007/s00280-007-0428-5.

22. Liu G, Franssen E, Fitch MI, Warner E. Patient preferences for oral versus intravenous palliative chemotherapy. J Clin Oncol. 1997;15(1):110-5. https://doi.org/10.1200/JCO.1997.15.1.110.

23. Eek D, Krohe M, Mazar I, Horsfield A, Pompilus F, Friebe R, et al. Patient-reported preferences for oral versus intravenous administration for the treatment of cancer: a review of the literature. Patient Prefer Adherence. 2016;10:1609-21. https://doi. org/10.2147/PPA.S106629.

24. Horgan AM, Knox JJ, Liu G, Sahi C, Bradbury PA, Leighl NB. Capecitabine or infusional 5-fluorouracil for gastroesophageal cancer: a cost-consequence analysis. Curr Oncol. 2011;18(2):e64-70.

25. Pashko S, Johnson DH. Potential cost savings of oral versus intravenous etoposide in the treatment of small cell lung cancer. Pharmacoeconomics. 1992;1(4):293-7. 